\title{
Employee retention in the Malaysian banking industry: Do flexible practices work?
}

\author{
M. Mansor ${ }^{a}$ and A Idris ${ }^{\text {b* }}$ \\ ${ }^{2}$ Human Resource Department, Arab Malaysian Bank, 50450 Kuala Lumpur. \\ bepartment of Business Policy and Strategy, Faculty of Business and Accountancy, University of Malaya, 50603 Kuala Lumpur \\ *To whom all correspondence should be addressed \\ aida idris@um.edu.my
}

\begin{abstract}
The objective of the study was to determine whether employee retention in Malaysian banks can be improved through flexible working. Using a quantitative approach, the effects of five types of flexible working practice, i.e. flex time, job sharing, flex leave, flex career and flex place, on employee retention were examined. The results suggest that only flex time has a positive significant effect on employee retention, while the effects of other flexible practices are unstable. Unlike most studies which generally demonstrate the positive effects of flexible working on employee retention, the current one indicates that the effectiveness of each flexible practice is influenced by contextual factors. These findings underline the importance of further studies comparing societies of different cultural, political, economic and technological backgrounds. They have also raised the need to re examine human resource management and organizational culture in the Malaysian work environment. Challenges lie in developing a flexible environment which values continuous learning, trust, accountability and strong corporate governance.
\end{abstract}

\section{Introduction}

Current trends in employee retention have risen largely due to changes in workforce demographics, such as the increasing role of Generation $Y$ and female employees who have introduced a different set of personal needs and work values (Benligiray \& Sonmez, 2013; Olmsted \& Smith, 1997; Vaiman, Scullion \& Collings., 2012; Williams \& Jones, 2005). Particularly in Europe and the United States, flexible working practices were first implemented in the public sector mainly as a response to these changes. These days flexible working is often used by companies as a sustainable competitive advantage over other firms vying for the same pool of talents (Arvinitis, 2005).

According to Cully, Woodland, O'Reilly and Dix (1999), flexible working includes part-time work, flex time, jobsharing and home-working which may be of benefit to employees with or without children. Organizations that are able to provide flexibility and alternative work schedules to cater to different personal needs and values have an edge since they can successfully attract qualified applicants who cannot, or do not want to, work a traditional schedule. Alternative schedules also help to attract other sub-groups in the workforce, such as dual-income couples who share family responsibilities, individuals who are pursuing further education, and persons with disabilities who are unable to conform to traditional work hours (Hammer \& Barbera, 1997).

Tietze and Musson (2002) define flexibility as both formal and informal policies which allow workers temporal flexibility in their work schedules by breaking away from the normal forty-hour 9-to-5 workweek. It includes flex time (Swart, 1978), job-sharing (Hunt, 1999; Mattis, 1990), career part-time (O'Hara, 1994) and telecommuting (Avery \& Zabel, 2001). However, in most studies, these substantially different practices are grouped under the universal term of flexibility or flexible work. Hence their findings do not include information on the individual effects of each type of flexible practice on employee retention.

This paper adopts the position that there is a need to examine different types of flexible practice separately since they offer varying degrees of advantage to different individuals and organizations. In the study five common types of flexible working practice, i.e. flex time, jobsharing, flex leave, flex career and flex place, were measured and their effects on employee retention were analyzed explicitly. The research objective was to determine the strength and direction of association between each type of flexible practice and employee retention, while focusing on the Malaysian banking sector due to its highly competitive nature where talent is concerned (Tajuddin \& Ahmad Saufi, 2012; Tower Watson Data Services, 2012).

Findings of the study are expected to help human resource managers and policy-makers in the Malaysian banking industry design and implement more effective employee retention strategies through flexible working. Furthermore differences in cultural values, technological advancements and developments in legal frameworks suggest that the effects of flexible working practices on employee retention may also differ significantly among nations. For instance, the Regus Global Report (2011) shows that while $53 \%$ of Belgian managers believe that flexible working improves 
employee motivation, only $43 \%$ of South African managers share the same opinion. Thus the current study is also expected to enhance knowledge of flexible working in a non-western setting.

\section{Flexible working and employee retention}

Shekshnia (1994) considers employee retention as all-round human resource strategies of an organization to attract and keep in its employment the best workers. Later, Freyermuth (2004) extends the concept as a continuous process that begins with recruiting the right people and continues with programs to keep employee engaged and committed to the organization. More recently, Chaminade (2007) defines employee retention as a voluntary move by an organization to create an environment which engages employees over a long period. Thus employee retention may be summarized as a long-term initiative by employers to ensure that the best individuals choose to join their organizations and continue to remain with them.

According to researchers (Gentry, Kuhnert, Mondore \& Page, 2007; Samuel \& Chipunza, 2009; Sigler, 1999), retention of employees is critical for organizations to maintain a source of competitive advantage since the loss of talented employees can be detrimental to the productivity of the business. Furthermore, because a great deal of money is spent on recruitment and training, the need to retain employees has become doubly important to their bottomline. Thus, in recent years, employee retention strategies and programs have been a topical area in human resource management research.

Current trends in the labor market have seen an ageing of the labor force and a gradual retirement of baby boomers. These and other demographic factors, such as an increasing participation of women in the workforce, particularly those with children, are posing challenges for organizations in planning their employee retention strategies (Williams \& Jones, 2005). Recognizing the need to provide a balance between work and life has led to an increased interest in flexible working arrangements and family-friendly policies among modern organizations. Flexible working practices are now often used to help businesses compete with other firms in getting the best workers (Arvanitis, 2005; Gholipour, Bod, Zebtabi, Pirannejad \& Kozekanan, 2010).

In their review of literature, Scandura and Lankau (1997) have found that flexible work schedules offer benefits such as higher job enrichment, job satisfaction and productivity, as well as lower stress, tardiness and absenteeism. For employees, greater job satisfaction and earnings, besides less work-family conflict, are certainly appealing (Baltes, Briggs, Huff, Wright, \& Neuman, 1999; Cao, 2005; Gariety \& Shaffer, 2001). Flexible working also gives the opportunity for employees to work according to their biological clock (Grensing-Pophal, 1993; Nollen, 1982; Olmstead \& Smith, 1994; Ronen, 1981), reduce costs of commuting (Nollen, 1982; Ronen 1981) and spend more time on family and leisure activities (Friedman, 1991; Ronen, 1981).

Advantages of flexible working enjoyed by employees in turn generate positive effects for employers. Besides producing lower absenteeism and a higher rate of employee retention, flexible working also allows workers to pursue continuous learning which ultimately adds to organizational knowledge. Studies have shown that human resource practices which improve employees' wellbeing also increase organizational performance (Baptiste, 2008). In particular, Chen and Huang (2009) demonstrate that strategic human resource practices such as flexible working enable organizations to build greater knowledge management capacity which enhances their innovation performance. Despite these advantages, however, the implementation of flexible working practices often faces resistance by managers as a result of their lack of trust for employees (Regus Global Report, 2011). Some managers also remain skeptical of the actual contributions of flexible working toward the organization (Duxbury \& Haines, 1991; Regus Global Report, 2011).

\section{Hypotheses}

Tietze and Musson (2002) conceptualize flexible practices as both formal and informal work systems that allow workers temporal flexibility in their work schedules. Generally, flexible practices enable organizations to work beyond the normal forty-hour 9-to-5 workweek. Typical dimensions of flexible practices include flex time (Swart, 1978), job sharing (Hunt, 1999; Mattis, 1990), flex career (O'Hara, 1994), and telecommuting (Goldenhar, 2003).

According to Cully et al. (1999), various components of flexible working such as part-time work, flex time, jobsharing and home-working, bring different benefits to different groups of employees. However, in most studies, these substantially different flexible practices are often measured and analyzed as a single, universal construct labeled as flexibility or flexible work. Therefore the theoretical differences among these various types of flexible practice have not been examined adequately through empirical research. The current study attempted to address this gap in the literature by separately measuring and analyzing five most common flexible working practices i.e. flex time, job sharing/part-time work, flex leave, flex career and flex place or telecommuting. Based on extant literature, these five constructs of flexibility can be summarized as follows.

1. Flex time: A scheduling option that allows employees to choose the time they start and stop work each day, within limits established by the management. Normally it specifies a certain amount of core hours when all employees must be present in the office. In other words, although the start-and-stop times may vary among employees, they are still required to work a standard number of hours each day to facilitate teamwork (Avery \& Zabel, 2001). Flex time provides 
flexibility in work schedule on a daily basis, and helps employees to cope with routine challenges such as traffic congestion, school-going children, et cetera.

2. Job-sharing/part-time: A popular flexible working arrangement, whereby two employees voluntarily share one full-time position with pro-rated salaries and benefits. Under job- sharing, each employee works parttime and is called a 'partner'. It can also be defined as an arrangement in which two or three people share a 40hour workweek among them (Robbins and Judge, 2007). For example, one may work in the morning and the other in the afternoon, or they can each take alternate days. In contrast to temporary or seasonal parttime workers, these employees are on a company's regular payroll and may receive other benefits including annual and maternity leave, health insurance, et cetera. This type of flexible practice helps to attract employees who cannot commit to the whole work duration every day, such as university students and mothers without full day-care for their children.

3. Flex leave: This is defined as paid leave for personal or family reasons (Institute of Management and Administration, 2005). It is considered as time away from work that has been earned and for which an employee is paid, and includes sick leave, vacation leave and compensatory leave. Although it is not effective as a long-term solution for work-family conflicts, flex leave is appropriate for employees who suddenly need to take a short time off to attend to an emergency situation such as a sick child or a traffic accident.

4. Flex career: An option that allows workers multiple entry points to their career by interspersing full-time with part-time work, and to spend some time out of work attending to family responsibilities or professional development (Hardy, 2008). It can be attractive to employees who wish to pursue further studies, yet have no intention to leave the organization upon completion of their study. It is also useful for those who have to go on an extended leave without any wish to resign from their jobs.

5. Flex place or telecommuting: It describes an arrangement where an employee performs some or all of his/her work at a location other than the regular worksite (Goldenhar, 2003). Since the internet and information technology have transformed communication, learning and working philosophies and systems (Baloh \& Trkman, 2003), telecommuting enables employees to work from home or a satellite office. This practice helps employees to overcome work challenges related to the geographical distance between home and office, marketing and technical jobs which require site visits, overseas appointments, et cetera.

From the above conceptualization of flexible working practices, it may be deduced that each type of flexible practice has the potential to improve employee retention, but each in a different way. Consequently, the following five hypotheses are forwarded.

$H_{1}$ : Flex time has a significant positive effect on
employee retention.

$\mathrm{H}_{2}$ : Part time work/job sharing has a significant positive effect on employee retention.

$\mathrm{H}_{3}$ : Flex leave has a significant positive effect on employee retention.

$H_{4}$ : Flex career has a significant positive effect on employee retention.

$H_{5}$ : Flex place has a significant positive effect on employee retention.

\section{Methodology}

\section{Data collection and sample}

A report by Tower Watson Data Services (2012) shows that the Malaysian banking sector suffered an increase in employee turnover from $11 \%$ in 2010 to $15 \%$ in 2011 , despite a $5.3 \%$ increment in salary. With its rigid operating systems and structures, this sector poses interesting questions about the effectiveness of flexible practices as an employee retention strategy. Furthermore, from the perspective of developing nations, scarce empirical research has been conducted to facilitate the formulation of effective employee retention strategies for business organizations. Thus, the problem statement of how each type of flexible practice affects employee retention in the Malaysian banking sector begs immediate investigation.

A quantitative approach was chosen for the study because of its statistical advantages in hypotheses testing (Johnson et al., 2007; Tashakkori \& Teddlie, 2003). Eight hundred copies of closed-ended questionnaires were evenly distributed to employees of eight major banks in Kuala Lumpur, the capital and commercial centre of Malaysia, within a period of two months. Altogether 120 completed questionnaires were returned, yielding a $15 \%$ response rate. The survey instrument consisted of three parts: profile of respondents, flexible working practices (independent variables) and employee retention (dependent variable). The measures of independent and dependent variables will be discussed shortly while a profile of the respondents is briefed as follows.

Out of the total number of respondents, females formed a clear majority $(71.7 \%)$. The largest age group came from the age bracket of $31-40$ years $(40.8 \%)$ followed by $21-30$ years $(35 \%)$, indicating a relatively young group of employees. More than half of the respondents were parents $(53.3 \%)$ while the remaining were either single or married but without children (46.7\%). About three-quarters of them represented a well-educated workforce and held at least a first degree qualification. This high level of education was 
also reflected in their job designation, where $60 \%$ of the respondents worked as executives and $32.5 \%$ were managers.

The final two demographic factors were concerned with the line of business and length of service of the respondents. In the banking industry, a line of business refers to a particular category of products and services offered by a bank. Typical lines of business inelude Retail/Commercial Banking, Business Banking, Investment, Shared Services and Insurance. In the current study, Retail/Commercial Banking topped the list $(38.3 \%)$, followed by Shared Services $(28.3 \%)$ and others $(25.8 \%)$. As for experience, $33.3 \%$ of the respondents had been working for less than two years, $28.3 \%$ between two and five years, and $38.3 \%$ for more than five years.

Apart from analyzing the respondents' profile, this part of the instrument also attempted to gauge their awareness of flexible working practices. When asked whether they were familiar with the concept of flexible working practices,

Table 1: Measures of independent and dependent variables
$98.3 \%$ or 118 responded in the affirmative. Thus the relevance of the current sample was assured, and the research then proceeded to the next stage of analysis.

\section{Measures}

Respondents were asked to rate their opinion on all items measuring independent and dependent variables, according to a five-point Likert scale ranging from one (strongly disagree) to five (strongly agree). Items selected for the survey instrument were adapted from previous studies (Avery \& Zabel, 2001; Hunt, 1999; Mattis, 1990; O'Hara, 1994; Swart, 1978; Vandenberg et al., 1999) and are listed in Table 1. Questions on flexibility asked respondents to evaluate the implementation of five types of flexible practice at their organization, while items on employee retention measured their satisfaction and intention to remain with the organization.

Independent variable: Flexible practices

1.Flex time:

It is implemented in my organization.

Its implementation is sufficient for my needs.

I feel encouraged by the organization to take advantage of it.

2. Part time work/job sharing

It is implemented in my organization.

Its implementation is sufficient for my needs.

I feel encouraged by the organization to take advantage of it.

3. Flex leave

It is implemented in my organization.

Its implementation is sufficient for my needs.

I feel encouraged by the organization to take advantage of it.

4.Flex career

It is implemented in my organization

Its implementation is sufficient for my needs.

I feel encouraged by the organization to take advantage of it.

5.Flex place

It is implemented in my organization.

Its implementation is sufficient for my needs.

I feel encouraged by the organization to take advantage of it.

1. I am happy to work for this organization.

2. I am enthusiastic about the work that I do here.

3. I intend to remain with this organization in the foreseeable future.

4. I feel valued by the management.

5. I am not looking for career opportunities in another organization. 
Factor analysis was conducted to determine construct validity. The results demonstrated that for employee retention and each construct of flexible practice, all items loaded onto a single factor, thus assuring the validity of the construct. The reliability of each measure was determined by its Cronbach's Alpha. As evident from Table 1, all five constructs of flexible practice and one construct of employee retention showed acceptable levels of reliability, i.e. $>0.7$. Since none of the reliability scores could be improved by deleting any item, all items were retained for subsequent data analysis.

The mean value of each construct is also shown in Table 1. The means for flexible practices ranged from 7.74 (flex place) to 7.79 (flex career), 8.13 (job-sharing), 8.38 (flex time) and 9.73 (flex leave), suggesting fairly low levels of implementation of flexible working in Malaysian banks. On the other hand, the mean for employee retention at 18.30 implied that Malaysian banks have a moderate capacity for retaining their employees.

Table 2: Results of correlation analysis

\section{Data analysis}

The study used correlation and multiple regressions analyses to examine the relationships between five flexible practices and employee retention. While correlation tests are useful to determine the strength and direction of single relationships, multiple regressions allow for the examination of simultaneous effects of all five independent variables. The results of these analyses are discussed below.

\section{Results and discussion}

\section{Correlation}

Table 2 provides a summary of correlation results between each independent variable (flex time-TFT, part-time work/job sharing-TJS, flex leave-TFL, flex career-TFC and flex place-TFP) and the dependent variable (employee retention-TRet).

\begin{tabular}{|c|c|c|c|c|c|c|c|}
\hline \multicolumn{8}{|c|}{ Correlation Coefficient } \\
\hline & & TRet & TFT & TJS & TFL & $\mathrm{TFC}$ & TFP \\
\hline TRet & $\begin{array}{l}\text { Pearson Correlation } \\
\text { Sig. ( } 2 \text { tailed }) \\
\mathrm{N}\end{array}$ & $\begin{array}{r}1 \\
120\end{array}$ & $120^{.016}$ & $\begin{array}{r}.027 \\
120^{.766}\end{array}$ & $120^{.076}$ & $120^{.234}$ & $120^{.066}$ \\
\hline
\end{tabular}

\footnotetext{
*** Significant at $\mathrm{p}<0.10$
}

The correlation coefficients indicated that when the five types of flexible practice were analyzed individually, flex time and flex leave correlated positively with employee retention at the $10 \%$ confidence level. This suggests that flex time and flex leave, when analyzed individually, had a positive significant effect on employee retention. At the same time, job sharing/part-time work, flex career and flex place appeared to have negligible relationships with employee retention.

\section{Multiple Regressions}

The following equation was used to estimate the influence of the independent variables on the dependent variable:

$$
\begin{aligned}
& \mathrm{ER}=\beta_{0}+\beta_{1} \mathrm{FT}+\beta_{2} \mathrm{JS}+\beta_{3} \mathrm{FL}+\beta_{4} \mathrm{FC}+\beta_{5} \mathrm{FP}, \text { where } \\
& \mathrm{ER}=\text { Employee Retention }
\end{aligned}
$$

\author{
$\beta_{0}$ Constant \\ $\beta_{1}=$ Regression coefficient for the corresponding \\ independent term \\ $\mathrm{FT}=$ Flex Time \\ $\mathrm{JS}=$ Job Sharing \\ $\mathrm{FL}=$ Flex Leave \\ $\mathrm{FC}=$ Flex Career \\ $\mathrm{FP}=$ Flex Place
}

Table 3 displays the multiple regression results. All five independent variables simultaneously explained $10.2 \%$ of the variance (R-square) in employee retention, and their collective effect was significant based on the F-value of 2.594, $\mathrm{p}=0.029$ of the overall model. The low R-square value suggested that there were other factors besides flexible practices which contributed more toward employee retention in Malaysian banks. 
Table 3: Results of multiple regressions

Model Summary ${ }^{b}$

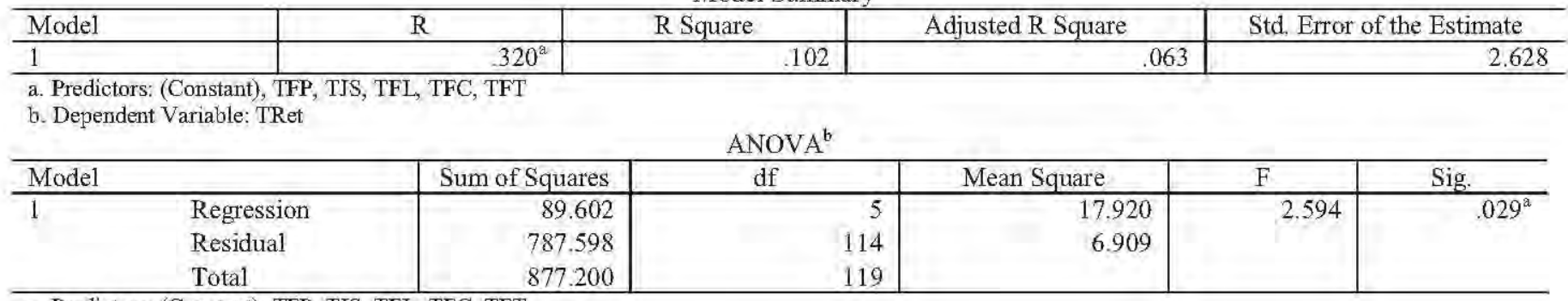

a. Predictors: (Constant), TFP, TJS, TFL, TFC, TFT

b. Dependent Variable: TRet

\begin{tabular}{|c|c|c|c|c|c|c|}
\hline \\
\hline & & \multicolumn{2}{|c|}{ Unstandardized Coefficients } & $\begin{array}{l}\text { Standardized } \\
\text { Coefficients }\end{array}$ & \multirow[b]{2}{*}{$t$} & \multirow[b]{2}{*}{ Sig. } \\
\hline \multicolumn{2}{|c|}{ Model } & $\mathrm{B}$ & Std. Error & Beta & & \\
\hline \multirow[t]{6}{*}{1} & (Constant) & 16.812 & 949 & & 17.722 & .000 \\
\hline & TFT & .449 & .153 & .466 & 2.927 & .004 \\
\hline & TJS &, 201 & .114 & .210 & 1.773 & .079 \\
\hline & TFL & .092 & .119 & .095 & .775 & .440 \\
\hline & TFC & .097 & .135 & .106 & .722 & .472 \\
\hline & TFP & 296 & .159 & .320 & 1.857 & 066 \\
\hline
\end{tabular}

a. Dependent Variable: TRet

Further examination of the individual p-values discovered that three types of flexible practice, i.e. flex time, jobsharing and flex place, had significant effects on employee retention at the $10 \%$ confidence level. However, in terms of direction of association, only flex time had a positive relationship with employee retention while job-sharing and flex place appeared to affect employee retention negatively. Also flex leave, which was found earlier to be positively correlated with employee retention, now had lost its significance. These results indicated that only flex time had a stable positive effect on employee retention, while flex career consistently showed a non-significant effect. On the other hand, the effects of job-sharing, flex place and flex leave were more unstable.

Based on the results of multiple regressions, the outcome of hypotheses testing is summarized in Table 4 . The regression equation for the overall model can be written as:

$$
\mathrm{ER}=16.81+0.47 \mathrm{FT}-0.32 \mathrm{FP}=0.21 \mathrm{JS}
$$

\section{Table 4: Results of hypotheses testing}

\begin{tabular}{|c|c|}
\hline Hypotheses & Result \\
\hline $\begin{array}{l}\mathrm{H}_{1}: \text { Flex time has a significant positive effect } \\
\text { on employee retention. }\end{array}$ & Supported \\
\hline $\begin{aligned} \mathrm{H}_{2}: & \text { Part time work } / \mathrm{job} \text { sharing has a } \\
& \text { significant positive effect on employee } \\
& \text { retention. }\end{aligned}$ & $\begin{array}{l}\text { Direction not } \\
\text { supported }\end{array}$ \\
\hline $\begin{array}{l}\mathrm{H}_{3} \text { : Flex leave has a significant positive effect } \\
\text { on employee retention. }\end{array}$ & Not supported \\
\hline $\begin{array}{l}\mathrm{H}_{4} \text { : Flex career has a significant positive effect } \\
\text { on employee retention. }\end{array}$ & Not supported \\
\hline $\begin{array}{l}\mathrm{H}_{5} \text { : Flex place has a significant positive effect } \\
\text { on employee retention. }\end{array}$ & $\begin{array}{l}\text { Direction not } \\
\text { supported }\end{array}$ \\
\hline
\end{tabular}

From the above, it is evident that not every type of flexible practice can improve employee retention. These results have contradicted the findings of earlier studies (Avery \& Zabel, 2001; Hunt, 1999; Mattis, 1990; O'Hara, 1994; Swart, 1978; Vandenberg et al., 1999) which suggest that all five types of flexible practice have positive significant effects on employee retention. The following reasons can be offered for the above anomalies.

Flex time is affirmed as an important contributor to employee retention among Malaysian bank workers due to its universal benefits to both individuals and organizations. Since flex time allows employees to adjust their work hours slightly according to their personal needs, it is popular among married employees who are usually occupied with their families early morning and late evening. At the same time, because they are still putting in the required number of core hours at the office, their performance in the organization is not compromised. Hence, it has become widely-accepted in Malaysian banks and actively implemented as an employee retention tool.

In contrast, flex place, flex leave, flex career and job-sharing involve a reduction in the total number of hours spent at the office. This situation leads to less physical interaction among members of the organization, a lower sense of belonging to the team, and a perception among other team members that the individuals involved do not contribute fairly to their collective needs. The issues of trust and accountability have possibly complicated matters. As such, in the Malaysian banking environment where operating hours and systems are fairly standardized, flex place, flex leave, flex career and job sharing are seldom encouraged by managers. 
The negative effects of job-sharing and flex place observed in the multiple regressions analysis were highly unexpected given that both literature review and the above correlation tests produced positive results. Clearly, the unstable effects of job-sharing, flex place and flex leave, as well as the consistently non-significant effect of flex career, warrant further investigation. To this end, future researchers may wish tô consider a qualitative approach to facilitate a more in-depth exploration of the research context which includes differences in politics, economy, culture and technology between developed and developing countries.

\section{Implications}

Findings of the study have both theoretical and practical implications to researchers, managers and policy-makers. Since the above model is able to explain only $10 \%$ of the variation in employee retention, future researchers should be motivated to explore other potential predictors, which include organizational characteristics and culture (such as human resource management systems, trust and accountability, learning orientation, et cetera). The findings also suggest that the effectiveness of each flexible working practice highly depends on contextual factors, such as sociocultural values and online communication facilities, within a particular society. Therefore, more comparison studies across societies of different cultural, political, economic and technological backgrounds are strongly encouraged.

To managers and policy-makers, the study has raised the need to re-examine human resource practices and work systems in Malaysia, particularly for firms operating internationally. Nowadays many local banks are already exploring means and strategies to adapt their operating systems to suit international business needs round-the-clock. Thus, operating twenty-four hours a day may be a norm in the future which will further strengthen the importance of flex time in employee retention. However, competing globally also calls for a more educated workforce with a high learning orientation. This means enhancing other flexible practices such as flex place, flex leave, flex career and job-sharing which allow employees to pursue training and professional development courses without having to sacrifice their jobs. Here, the challenge will be in developing an organizational culture which values continuous learning, trust, individual rights and good corporate governance.

\section{Conclusion}

The current study was carried out to examine the effects of five types of flexible working practice on employee retention in the Malaysian banking industry. Its significance may be seen in the following ways: one, it can serve as a comparison with similar studies done in other countries with different cultural, economic, political and technological backgrounds; two, it has highlighted trends specific to the banking sector, which is one of the most globalized and competitive businesses today; and three, unlike most studies which tend to measure and analyze all flexible practices as a single universal construct, it has distinguished the various effects of five different types of flexible practice.

Based on the findings, it may be concluded that although flexible practices do to a certain extent improve employee retention in Malaysian banks, there are clearly other factors such as operating systems, organizational culture and the macro-environment which wield a greater influence. The interplay among these additional variables and flexible working practices should make an interesting study for future researchers. Furthermore, despite affirming the importance of flex time, the study has shown that at present not all types of flexible practice are equally effective in employee retention. Due to their limited understanding of models and outcomes of flexible working, local organizations have not been able to realize most of its advantages. It is worth-noting that unless serious effort is taken by Malaysians to understand, develop and support effective flexible programs, national ideals such as continuous learning and work-family balance will continue to remain elusive.

\section{References}

Arvanitis, S. 2005. 'Modes of labor flexibility at firm level: are there any implications for performance and innovation? Evidence for Swiss economy", Industrial and Corporate Change, 14(6); 993-1016.

Avery, C. \& Zabel, D. 2001. The Flexible workplace: a sourcebook of information and research. London: Quorum Books.

Baloh, P. \& Trkman, P. 2003. 'Influence of internet and information technology on work and human resource management', Informing Science, June: 497-506.

Baltes, B.B., Briggs, T.E., Huff, J.W., Wright, J.A. \& Neuman, G.A. 1999. 'Flexible and compressed workweek: a meta-analysis of their effects on work-related criteria', Joumal of Applied Psychology, 51(6): 1173-182.

Baptiste, N.R. 2008. 'Tightening the link between employee wellbeing at work and performance: a new dimension for HRM', Management Decision, 46(2), 284-309.

Benligiray, S. \& Sonmex, H. 2013. 'The analysis of demographics and worklife variables which affect the occupational commitment of nurses', Journal of Management Development, 32(4): 419-434.

Branch, S. 1998. 'The new economy: You hire "em. But can you keep "em?", Fortune, Nor 9: 101-104.

Bush, B. J. 2001. 'People: attracting, retaining, and motivating", The Public Manager, $30(2), 31$.

Cao, F. 2005. Exploring the relations among availability of temporal flexibility at work, work to family conflict, and job 
satisfaction. Unpublished $\mathrm{PhD}$ Dissertation Southern Illinois University.

Chaminade, B. 2007. A retention checklist: how do you rate? Accessed 28 Sept 2012, Www. humanreourcesmagazine.co.au

Chen, C-J. \& Huang, J-W. 2009. 'Strategic human resource practices and innovation performance - The mediating role of knowledge management capacity", Joumal of Business Research, 62(1): 104-114.

Cohen, A. 1993. 'Age and tenure in relation to organizational commitment: a meta-analysis', Basic and Applied Social Psychology, 14; 143-159.

Cully, M., Woodland, S., O'Reilly, A. \& Dix, G. 1999. Britain at Work: As Depicted by 1998 Workplace Employee Relations Survey. London: Routledge.

Denton, K.D. 1992. Recruitment, Retention and Employee Relations. Connecticut: Quorum Books.

Duxbury, L, \& Haines, G. 1991. 'Predicting alternative work arrangements from salient attitudes: a study of decision-makers in the public sector', Journal of Business Research, 23(1): 83-97.

Freyermuth 2007. Retaining Employees in a Tightening Labor Market. RSM McGladrey. Accessed 16 Sept 2012 , www.cfo.com/whitepapers/ index.cfm/displaywhitepapers/ 10308654 ? topicid $=10240327-22 \mathrm{k}$ -

Friedman, D. E. 1991. Linking Work Family Issues to the Bottom Line. New York: The Conference Board.

Gariety, B.S. \& Shaffer, S. 2001. "Wage differentials associated with flextime", Monthly Labour Review, 124: 6875.

Gentry, W.A., Kuhnert, K.W., Mondore, S.P. \& Page, E.E. 2007. 'The influence of supervisory-support climate and unemployment rate of part-time employee retention: a multilevel analysis", Journal of Management Development, 26(10): $1005-1022$.

Gholipur, A., Bod, M., Zebtabi, M., Pirannejad, A. \& Kozekanan, S.F. 2010. 'The feasibility of job sharing as a mechanism to balance work and life of female entrepreneurs', International Business Research, 3(3): 133140.

Goldenhar, D. 2003. Advancing Women Professionals and The Jewish Community: The Benefits of Flexible Work Arrangements. New York: JBFCS.

Gottlieb, B. H., Kelloway, E. K., \& Barham, E. J. 1998. Flexible Work Arrangements: Managing the Work Family Boundary. Chichester: Wiley.
Grensing-Pophal, L. 1993. 'Flextime lets night owls and early birds soar', Office Systems, 10(6): 66-67.

Hammer, L. B. \& Barbera, K. M. 1997. 'Toward an integration of alternative work schedules and human resource systems', Human Resource Planning, 20(2), 28-36.

Hardy, M.A. 2008. 'Making work more flexible: Opportunities and evidence', Insight on the Issues, 11: 1-23.

Hunt, J. 1999. 'Has work-sharing worked in Germany?', Quarterly Journal of Economics, 114(1): 117-148.

Institute of Management and Administration, 2005. 'Personnel management: tactics designed to make flextime work', Design Firm Management and Administration Report, 5(3): 1-5.

Johnson, R.B., Onwuegbuzie, A.J. \& Turner, L.A. 2007. 'Toward a definition of mixed method research', Journal of Mixed Method Research, 1(2): 112-133.

Joubish, M.F., Khurram, M.A., Ahmed, A., Fatima, S.T. \& Haider, K. 2011. 'Paradigm and characteristics of a good qualitative research', World Applied Sciences Joumal, 12(11): 2082-2087.

Krippendorff, K. 2004. Content analysis: an introduction to its methodology, $2^{\text {nd }}$ edition. Thousand Oaks: Sage.

Mattis, M.C. 1990. "New forms of flexible work arrangements for managers and professionals: myth and realities', Human Resource Planning, 13: 133-146.

Nollen, S. D. 1982. Work schedules in practice: managing time in a changing society. New York: Van Nostrand Reinhold.

O'Hara, B. 1994. Put work in its place. How to redesign your job to fit your life. $2^{\text {nd }}$ edition. Vancouver: New Star Books.

Olmsted, B. and Smith, S. 1994. Creating a flexible workplace: how to select and manage alternative work options. $2^{\text {nd }}$ edition. New York: AMACOM.

Olmsted, B. and Smith, S. 1997. Managing in a flexible workplace. New York: American Management Association.

Regus Global Report, 2011. Flexible working goes global. Accessed 6 August 2012, www.regus.presscentre.com

Robbins, S.P. and Judge, T.A. 2007. Essentials of organizational behaviour. $6^{\text {th }}$ edition. Saddle River: Prentice Hall.

Ronen, S. 1981. Flexible work schedules: an innovation in the quality of work life. New York: McGraw-Hill. 
Samuel, M.O. \& Chipunza, C. 2009. 'Employee retention and turnover: Using motivational variables as a panacea", African Joumal of Business Management, 3(8): 410-415.

Scandura, T. A. \& Lankau, M. J. 1997. 'Relationships of gender, family responsibility and flexible work hours to organizational commitment and job satisfaction', Journal of Organizational Behavior, 18(4): 377-391.

Shekshnia, S. 1994. 'Managing people in Russia: challenges for foreign investors', European Management Journal, 12: 298-305.

Sigler, K.J. 1999. 'Challenges of employee retention', Management Research News, 22(10), 1-5.

Swart, J.C. 1978. A flexible approach to working hours. New York: AMACOM.

Tajuddin, D. \& Ahmad Saufi, R. 2012. A preliminary study of the validity of talent management practices, talent brand strategies and employee value proposition in the Malaysian banking industry. Proceedings of the $3^{\text {rd }}$ International Conference on Business and Economics Research. Bandung, Indonesia, 12-13 March.

Tashakkori, A. \& Teddlie, C. (Eds.) 2003. Handbook of mixed methods in social and behavioral research. Thousand Oaks: Sage.

Tietze, S. \& Musson, G. 2002. "When 'work' meets 'home": temporal flexibility as lived experience', Time \& Society, 11(2/3): 315-334.

Tower Watson Data Services, 2012. Financial services total rewards survey key insights for 2012. Accessed 5 August 2012, www.towerwatson.com/malaysia/research/6594

Vaiman, V., Scullion, H. \& Collings, D. 2012. 'Talent management decision making', Management Decision, 50(5): $925-941$.

Vanderberg, R.J., Richardson, H.A. \& Eastman, L.J. 1999. 'The impact of high-involvement work process on organizational effectiveness', Group \& Organization Management, 24(3): 300-339.

Williams, L. \& Jones, A. 2005. Changing demographics. UK: The Work Foundation. 